\title{
Cognitive Restructuring Techniques to Improve Student Self-Concept
}

\author{
Mufied Fauziah, Aprilia Setyowati \\ Department of Guidance and Counselling \\ Universitas Ahmad Dahlan \\ Yogyakarta, Indonesia \\ mufied.fauziah@bk.uad.ac.id
}

\author{
Irfan Fahriza \\ Department of Guidance and Counselling \\ Ma'soem University \\ Sumedang, Indonesia
}

\begin{abstract}
Self-concept is important for students, because it can affect various aspects of their lives. This study aims to test the effectiveness of group counselling with cognitive restructuring techniques to improve students' self-concept. The study used quasi-experimental research method with nonequivalent pre-test-post-test control group design. The data collection was done by using self-concept inventory. The sample collection used purposive sampling technique. The result of the study shows that group counselling with cognitive restructuring techniques is effective in improving students' self-concept.
\end{abstract}

Keywords-self-concept; group counselling; cognitive restructuring techniques

\section{INTRODUCTION}

Self-concept is one of the important aspects in adolescence. Adolescence is an important period, because individual experiences: (a) transitional period and seeking identity, (b) age that raises some concerns, (c) not real periods, (d) maturity period, and (e) problematic age[1]. If teenagers have failed in developing a sense of identity, then teenager will lose life direction, such as a ship that loses a compass.

According to Frik's research which involved male and female students who are paired based on the level of students' intelligence potential [2]. The research classifies the subject of research based on student achievement into two classification, they are overachievers and underachievers. The result of the research indicates that there are differences in self-concept between students who are classified as overachiever and underachiever. Overachievers show positive self-concepts, while underachievers show negative self-concepts. In the beginning of study at Al-Ma'soem SHS, there is a tendency for low self-concept. The low self-concept is reflected both in attitude and behaviour. The example is the number of students who do not have self-confidence in the physical condition, unable to express opinions in the class discussions and the raise of deviant behaviours such as aggressiveness, noisy, and being rude.

The Guidance and Counselling teachers are responsible and play a role in improving the service quality. Counselling and guidance service as one of the important parts in implementing education in the school has duties and responsibilities in guiding the students' development, including to develop students' self-concepts. Cognitive changes can be realized through specific cognitive [3]. Counselling can be done to improve students' self-concept through cognitive restructuring techniques. Negative effects due to negative self-views are changed through cognitive restructuring into positive thoughts. In order to improve the low self-concept, it has to improve the cognitive function at first.

Cognitive-behavioural counselling is an approach with some procedures, which specifically use cognition as the most important part of the counselling process. On the definition which is put forward by Matson \& Ollendick [4], the conducted counselling focuses on perceptions, beliefs and thoughts. In cognitive-behavioural counselling individuals are invited to oppose wrong thoughts and emotions by presenting evidences that are contradicting individual beliefs about the problem at hand.

The aim of cognitive-behavioural counselling in general is to help individuals to identify and change specific cognitive processes related to affective problems and behaviour. Cognitive restructuring is an alternative technique from behavioural cognitive counselling that has been developed by several cognitive behavioural experts, such as Michael and Donald Meichenbaum.

Cognitive restructuring assumes that non-adaptive behavioural and emotional responses are influenced by learners' beliefs, attitudes, and feelings. Cognitive restructuring focuses on identifying and changing negative thoughts or self-statements and irrational learner beliefs. The purpose of implementing cognitive restructuring techniques is to build an adaptive mind set. Cognitive restructuring focuses on identifying and changing cognitive errors or perceptions of students about themselves and the environment. Cognitive errors are expressed through negative self-statements. Negative self-statements indicate irrational thoughts, views, and beliefs.

The behaviour or emotion of a maladaptive person is influenced by the wrong thinking process [5]. Cognitive restructuring process can be done by identifying thinking errors in the form of self-criticism. Then proceed with rearranging one's mind by denying the criticism. 
There are three things that must be considered in the implementation of cognitive restructuring techniques [3]:

1. Identification of Students Negative Thoughts

Expresses the ability of students to identify negative thoughts requiring habituation and practice. Some students can quickly have "psychological minded" and understand the direction of school counsellors, but sometimes there are students who have difficulty identifying negative thoughts they have. School counsellors are required to be able to anticipate and prepare to respond to students' abilities and skills. The use of language in counselling can be modified to convince students of the importance of understanding and having positive thoughts about a situation.

Initially Students often present negative statements as a representation of their thoughts about the stimulus they are facing. School counsellors are required to be able to find more constructive and positive substitution statements.

2. Negative Thought Collection Method

Cognitive behavioural counsellors use the dysfunctional thoughts record (DTR). DTR is considered to be able to define the cognitive characteristics of learners. In the early stages of counselling, students can be asked to bring a small notebook that is useful for writing homework assignments, things related to treatment in counselling, and recording negative thoughts. The format proposed for recording negative thoughts is as follows.

3. Students Negative Thought Intervention

The intervention step of negative thoughts is given to students if the school counsellor has got a lot of information about negative thoughts of the students themselves. Some things about negative thoughts include the following.

a. Find negative thoughts related to strong emotional reactions.

b. Find thoughts related to strong behavioural response patterns.

c. Find thoughts that have a high level of confidence.

d. Finding repetitive thoughts, because the thoughts put forward repeatedly show students' thinking patterns.

Self-concept is a person's view of himself which includes understanding, assessment, and expectations regarding physical, psychological, and social aspects that are formed from learning outcomes and experiences so that they are sedentary and consistent.

Hurlock reveals self-concept as a configuration of perceptions that consists of beliefs, feelings, attitudes and values that students perceive as part of their own characteristics [6]. Self-concept is also interpreted by Hurlock as a system of meaning of students about themselves and the views of others towards him. There are three components of students' self-concept about themselves. a. Perceptual component: refers to students 'perceptions of their physical appearance, both students' perceptions of themselves and other people's perceptions that are perceived by the students concerned (mirror image).

b. Conceptual component: refers to students' conceptions of distinctive personal characteristics, including abilities and disabilities, background and origin, and future.

c. Attitudinal component: refers to the feelings of students about themselves, concerning attitudes about current status and future prospects, feelings of worthiness (attitude) towards self, adjustment, feeling of pride or shame.

Berzonsky revealed aspects of self-concept, as follows [7].

a. Physical indicators include; perspective on health, body appearance, and physical strength.

b. Psychic indicators include; perspective on academic ability, development of knowledge, feelings of self, and treatment of oneself.

c. Social indicators include; social roles in the school environment, place of residence, and community as well as the ability to do tasks at school and at home.

d. Moral indicators include a view of the values that apply in the surrounding environment.

Based on the phenomena and previous research it is necessary to research the effectiveness of cognitive restructuring techniques to improve students' self-concept.

\section{METHOD}

This research uses a quantitative approach that is a type of scientific research in which the researcher decides what will be studied by asking specific or narrow questions, collecting data that can be quantified, analysing the numbers using statistics and conducting research in a way objective. The variable in this study is the cognitive restructuring technique as an independent variable and self-concept as dependent variable.

The research method used is quasi-experimental method. The quasi-experimental research design experimental studies but not the function fully to control or control variables that could affect the experiment. In quasi experiments is not using random techniques (random assignment) but rather grouping based on previously formed groups [8]. The research design is non-equivalent pre-test-post-test group design which participants grouping into two groups namely, the control and experiment groups. Placement was done randomly, then each group was given a pre-test and post-test.

The research was conducted at Al-Ma'soem High School, Jatinangor. The population of all students of class XI of SMA Al-Ma'soem in Academic Year 2018-2019 with a total of 298 students. The sampling technique used was purposive sampling technique, a technique to determine the sample with certain characteristics.

The sample study was 66 students of class XI at SMA A1Ma'soem in Academic Year 201-2019 who were identified as 
having a low self-concept. As for the pre-test giving to students of class XI. Pre-test which ones have low selfconcept.

The stages of implementation of cognitive restructuring techniques implemented to improve students' self-concept in this study refer to the opinions of Cormier \& Cormier as follows [2]:

1. First stage: Assessment and diagnosis. Assessment and diagnosis in the early stages aims to obtain data about the condition of the students to be dealt with and anticipate the possibility of mishandling in the counselling process

2. The second stage: identifying negative thoughts of learners. Before students are given assistance to change the thoughts that are dysfunctional, first the school counsellor needs to help students to realize the dysfunctions of the thoughts that students have and notify directly to the school counsellor. At the general level, students are encouraged to return to experience and do introspection or reflect on experiences that have been passed.

3. The third stage: monitor the thoughts of learners through thought record. In the third stage, students are asked to bring a small notebook that is useful for writing homework assignments, matters relating to treatment in counselling, and recording negative thoughts. Formats can be made by students or prepared by school counsellors as a format that has been printed on the paper submitted to record negative thoughts of students.

4. Fourth stage: provide feedback to students and provide motivation to attend Counselling to the end. In the fourth stage school counsellors explain to students about the development of students after undergoing three stages of counselling. School counsellors provide feedback on learners' behaviour as well as things that occur during counselling so students are able to understand the experience and be aware of cognitive conditions that are wrong in perceiving and reacting to the stimulus they are facing.

5. Fifth stage: intervention negative thoughts Students become positive thoughts. In the fifth stage, negative thoughts of students who have accumulated in thought records are modified and given intervention.

The intervention was carried out within two weeks, divided into six sessions in which each session was 90 minutes long.

The research hypothesis was formulated that there is a positive effect of cognitive restructuring techniques on students' self-concept. The data analysis technique in this study used the dependent T-test (correlated sample).

\section{RESULTS AND DISCUSSION}

Self-concept can be indicated from several aspects, namely: (1) Physical; (2) Psychic; (3) Social; and (4) Moral. Based on the results of research on 298 students, it was found that the achievement of the average self-concept of all students in aspect 1 (Physical) was 47.93\% aspect 2 (Psychic) of $57.51 \%$, aspect 3 (Social) was $58.72 \%$, and aspect 4 (Moral) of $78.45 \%$. overall the four aspects of self-concept in students tend to be high. The lowest percentage is the first aspect which is physical at $47.47 \%$, while the highest percentage is the fourth aspect, namely the moral aspect. There is a difference in the score of the respondent's selfconcept at the pre-test and post-test, as shown in Table 3.1. as follows.

\section{TABLE I. PRE-TEST AND POST-TEST SCORES}

\begin{tabular}{|l|l|l|l|l|}
\hline \multirow{2}{*}{ Aspect } & \multicolumn{2}{|c|}{$\begin{array}{c}\text { Experimental } \\
\text { Group }\end{array}$} & \multicolumn{2}{c|}{ Control Group } \\
\cline { 2 - 5 } & $\begin{array}{l}\text { Pretest } \\
\text { mean }\end{array}$ & $\begin{array}{l}\text { Posttest } \\
\text { mean }\end{array}$ & $\begin{array}{l}\text { Pretest } \\
\text { mean }\end{array}$ & $\begin{array}{l}\text { Posttest } \\
\text { mean }\end{array}$ \\
\hline Physical & 0.87 & 2.04 & 0.86 & 1.38 \\
\hline psychic & 2.19 & 4.38 & 2.28 & 3.28 \\
\hline Social & 1.66 & 2.71 & 1.76 & 2.04 \\
\hline Morals & 0.71 & 0.95 & 0.76 & 0.80 \\
\hline
\end{tabular}

Data analysis performed by correlated t-test techniques shows the t-count of 4.317 with the level of sig. (2-tailed) $=$ 0.001 at $\mathrm{df}=12$, at the significance level $(\alpha=0.05)$. From the calculation results show that $\mathrm{t}$-count is more than table, which is $4.317 \geq 1.782$.

Based on the results of the study, it was obtained data that most students had a high self-concept, and only around $22.23 \%$ or 66 students had a low self-concept. This is in accordance with the data from the observations made during the study of students and teachers at the school. The high selfconcept of most students is the result of school efforts through several activities that must be followed by students from the beginning of learning activities, in which activities are given non-academic materials that can support the development of good self-concepts.

Thus, it seems that these students have sufficient provisions in stabilizing their concepts. But due to lack of experience and various environmental influences, there are still a small number of students who have low self-concept. The low self-concept possessed by a small number of students is not a thing that must be left out. This is because every student has the potential to have a good self-concept in order to achieve success in his life. This is in accordance with Rogers's opinion that self-concept plays a central role in human behaviour, and the greater the compatibility between self-concept and reality the less the inability to adjust to others [7]. In Rogers's opinion, it can be understood that students 'self-concept will influence students' behaviour in interacting with the environment. The more positive selfconcept means the easier it is for students to interact with the surrounding environment both in school and society. In addition, in adolescence they have a tendency to conformity, namely the tendency to give up or follow opinions, opinions, values, habits, interests or desires of others (peers). The development of conformity attitudes in adolescents can have a positive or negative impact on him. So, if not given reinforcement, students who have a low self-concept can influence students who have a good self-concept.

Providing Counselling services to improve students' selfconcept can be done using cognitive restructuring. The purpose of implementing cognitive restructuring techniques is 
to build a more appropriate or adaptive mind set. Cognitive restructuring focuses on efforts to identify and change cognitive errors or perceptions of learners about themselves and the environment. Cognitive errors are expressed through negative self-statements. Negative self-statements indicate irrational thoughts, views, and beliefs.

According to McKay and Fanning, [8] the process of cognitive restructuring can be done by identifying thinking errors in the form of self-criticism [9]. Then proceed with rearranging one's mind by denying the criticism. Yahav and Cohen revealed that the behaviour or emotions of a maladaptive person are influenced by the wrong thinking process. So that this technique is felt appropriate to facilitate the improvement of students' self-concept for the better [5].

Judging from the scope of guidance and counselling in general, cognitive restructuring technique is the provision of treatment with cognitive behavioural counselling is the embodiment of the field of academic guidance (learning) and prevention and healing functions of counselling and counselling, as well as the implementation of group counselling services.

Berzonsky revealed that [1] aspects of self-concept include: (1) Physical; (2) psychic; (3) social; and (4) morals. Based on the results of the study, the most identified aspects of the respondents were the first aspect, namely the physical aspect. This means that students have a tendency to have a negative perception of their physical. The manifestation of a low self-concept in the physical aspect can be in the form of insecurity, or not paying attention to his appearance at all. After following the intervention through cognitive restructuring, it was seen an individual's perception of himself, his appearance (beautiful, attractive, ugly) and his condition (short, fat, thin) had increased, this was seen by the change in behaviour of students who already had a positive outlook on physical life. The things that change are students begin to pay attention to or maintain a healthy body, have good self-confidence, and accept their physical condition.

\section{CONCLUSION}

Based on the research data, it shows that there is a significant increase from the average pre-test score to the post-test score. Thus, effective cognitive restructuring techniques to improve self-concept of class XI students of Al-Ma'soem High School Academic Year 2018-2019.

\section{REFERENCES}

[1] E. B. Hurlock, Child Development, Michigan: McGraw-Hill Education, 1972.

[2] W. Cormier dan L. Cormier, Interviewing Strategies For Helpers: Fundamental Skill Cognitive Behavioral Interventions, Monterey, California: Brooks/Cole Publishing Company, 1985.

[3] D. Dobson dan K. Dobson, Evidance-Based Practice of Cognitive Behavioral Therapy, Newyork : The Guilford Press, 2009.

[4] J. L. Matson dan T. H. Ollendick, Enhancing Children's Social Skill: Assessment and Training, New York : Pergamon Press, 1988.

[5] R. Yahav dan M. Cohen, "Evaluation of Cognitive behavior intervention for adolescents," International Journal of Stress Management, vol. 15, no. 2, pp. 173-188, 2008.

[6] G. R. Adams dan M. Berzonsky, Blackwell Handbook of Adolescence, Victoria: Wiley-Blackwell, 2003

[7] J. W. Creswell, Research Design: Qualitative, Quantitative, and Mixed Methods Approaches, California: Sage, 2014

[8] M. McKay dan Fanning, Self-esteem, Canada: New Harbinger Publications, Inc., 2000.

[9] Oemarjoedi, K.A. (2003). Pendekatan Cognitive Behavior Dalam Psikoterapi. Sumedang: Penerbit Creativ Media. 